\title{
Association Between Anthropometric \\ Measurements and the Amount of Fat Aspirated in Waist and Abdominal Liposuction: A 20-year Retrospective Study
}

\author{
Fan Yang \\ Fourth Military Medical University: Air Force Medical University \\ Wenjie Dou \\ Fourth Military Medical University: Air Force Medical University \\ Liwei Peng \\ Fourth Military Medical University: Air Force Medical University \\ Wangzhou Li \\ Fourth Military Medical University: Air Force Medical University \\ Yuejun Li ( $\square$ liyj@fmmu.edu.cn ) \\ Fourth Military Medical University: Air Force Medical University
}

\section{Research}

Keywords: liposuction, waist circumference, abdominal subcutaneous fat, anthropometry, retrospective studies

Posted Date: March 18th, 2021

DOl: https://doi.org/10.21203/rs.3.rs-310612/v1

License: (c) (i) This work is licensed under a Creative Commons Attribution 4.0 International License.

Read Full License 


\section{Abstract}

Background: Previous studies revealed that larger liposuction volumes were related to an increased risk of complications. However, no concrete data exist to support the most critical factor which affects the liposuction volume in the waist and abdominal area. This study was undertaken to investigate the relationship between the anthropometric measurements and lipoaspirate volume.

Methods: The present study was a single-center retrospective study. 742 patients who met the inclusion and exclusion criteria in our hospital, from January 2001 to August 2020, were reviewed. Spearman correlation analyses and multivariable regressions were used to assess the relationship between the anthropometric measurements and lipoaspirate volume. Linear-by-linear association chi-square statistic and Goodman-Kruskal gamma method were used to test the consistency and to develop a rank prediction formula.

Results: A total of 742 patients aged 18-59 years old met the inclusion criteria. Among all the anthropometric measurements, the highest correlation coefficient was observed in waist circumference. Subgroup analyses indicated that there was an interaction between the BMI and waist circumference on liposuction volume. Formula was generated to estimate the range of liposuction volume based on the nine grouped waist circumferences [liposuction volume (mean) $=106.3$ waist circumference (mean) $7497, \mathrm{P}<0.001$, adjusted $\left.\mathrm{R}^{2}=0.9638\right]$.

Conclusions: Waist circumference was the most influential factor for lipoaspirate volume. Roughly predicting the lipoaspirate volume allows surgeons to estimate their operating volume even if no iconography machine is available during suction-assisted lipectomy. This can increase safety, potentially decreasing the number of adverse events.

\section{Introduction}

Liposuction, as one of the most commonly performed cosmetic surgical procedures worldwide (1), has been regarded as a viable procedure to improve human body shape and contour especially in female individuals(2). For obese patients who received large-volume liposuction (LVL), in which a lot of subcutaneous fat has been sucked out of the body, it could be also beneficial to her/his health with decreasing risk of cardiovascular disease, diabetes, hypertension and other obesity-related diseases.(3).

The volume of fat in aspirate removed by a single surgery is often used as one of the important reference factors to assess the complexity and security of a liposuction procedure, and many adverse events have been directly associated with the LVL, including necrotizing fasciitis, fat embolism and deep vein thrombosis(4-11). More fat extraction always requires more infiltrated tumescent fluids with higher dosages of lidocaine and epinephrine, and longer operation time(12-16). Also, substantial hemodynamic responses may occur in patients with $L V L$ during the perioperative period, including an increase in mean pulmonary arterial pressure, cardiac index, and heart rate $(17,18)$. 
So far, there have been no scientific data to support a specific volume maximum at which point liposuction is considered unsafe(19). However, in response to the complications associated with liposuction, safety restrictions or guidelines on lipoaspirate volume have been released by national health administrative authorities or related professional societies. The American Society of Plastic Surgeons (ASPS) defines large-volume liposuction as greater than $5000 \mathrm{ml}$ during a single procedure in guidelines(20). In china, the liposuction volume is also being used as the basis of surgery grading for liposuction in the catalogue of classification Management issued by the Ministry of Health (21).

So, if the fat volume to be removed for a liposuction procedure can be accurately estimated preoperatively, it will be very helpful to the doctor-patient communication, the formation of the surgical strategy and the risk assessment of the potential complications.

In this study, a retrospective analysis of 742 cases in a single center was conducted to explore the associations between the liposuction fat volume and preoperative clinical data including age, height, weight, BMI, WC and WHtR, for the purpose to find out which one is the key factor closely related to the amount of fat aspiration. In addition, we tried to establish a feasible scheme for predicting the amount of fat in aspirate using the anthropometric measurements obtained before the operation.

We present the following article/case in accordance with the CONSORT reporting checklist.

\section{Methods}

\section{Data collection}

The clinical data of the consecutive patients met the inclusion and exclusion criteria from January $1 \mathrm{st}$ 2001 to August 30st 2020 at the Tangdu Hospital were reviewed. Inclusion criteria: (1) female patients, aged 18 to 60 years old; (2) with negative pressure assisted liposuction in waist and abdomen, and the surgery area was defined as: up to the plane of the inframammary folds, down to the inguinal folds and with bilateral boundaries to left/right vertical line of the posterior axillary fold, as shown in Fig. 1.

Exclusion criteria: (1) secondary repair surgery; (2) simultaneously with other surgery; (3) with incomplete data.

\section{Variables}

The liposuctioned fat volume, age and preoperative anthropometric measurements of height, weight, waist circumference were inputted into an Excel file (Microsoft Excel 2010 software) according to the medical records of each case. Body mass index (BMI) was calculated as weight in kilograms $(\mathrm{kg})$ divided by height in meters squared $\left(\mathrm{m}^{2}\right)$ and waist-to-height ratio (WHtR) was calculated as WC $(\mathrm{cm})$ divided by height $(\mathrm{cm})$. The value of WC was the circumference measured at the iliac crest level during the end of natural exhalation and the beginning of inhalation (Fig. 2), and the fat volume was the amount of fat in aspirates, still standing for at least 30 minutes after the end of liposuction.

\section{Statistical analyses}


First, clinical and demographic variables were tested for normal distribution by the Shapiro-Wilk test and are presented as median and interquartile ranges. Second, relations between anthropometric measurements and lipid volume were calculated using the spearman correlation coefficient. Third, partial correlations adjusted for weight, WHtR and BMI were applied to assess the relationship between the WC and other variables. Fourth, multi regression models were used to compare different preoperative measurements. Fifth, linear-by-linear association chi-square statistic was used to test linear correlation trend between two ordinal categorical variables and Goodman-Kruskal gamma statistic was used to measure the consistency. In the sensitivity analysis, we repeated analysis by (1) adjusting confounding factors (2) different subgroup analysis (3) getting rid of the outliers (Table S1)

All patients signed the informed consent form, and the study was approved by the Ethics Committee of Tangdu Hospital (No. K202103-05).

All analyses were performed by the statistical software packages R (http://www.R-project.org, The R Foundation) and EmpowerStats (http://www.empowerstats.com, X\&Y Solutions, Inc., Boston, MA). P values less than 0.05 (two-sided) were considered as statistically significant.

\section{Results}

\section{Descriptive analysis of the clinical data}

All the 742 cases were female, ranged from 18 to 59 years, and the average age was $36.34 \pm 8.73$ years old. Normality tests and descriptive statistics of age, height, weight, BMI, WC, WHtR and fat volume are listed in Table 1. After the normality tests, we found that such variables as age, height, weight, WC, BMI, $\mathrm{WHtR}$ and intraoperative liposuction volume were skewed distribution. The fat volume removed from the waist and abdominal areas and other variables are shown by a distribution histogram in Figure 3 . Fat volume was not a normal distribution (KS test, $\mathrm{P}<0.001$ ) but a positively skewed distribution with the long right-side tail, and the kurtosis and skewness were 2.759 and 1.431 respectively.

\section{Correlations between fat volume, age and other anthropometric measurements}

All the data were skewed distribution, thus, the Spearman correlation coefficients were used (Figure 4). There was a weak correlation between liposuction volume and age $(r=0.150, p<0.05)$, and there was no correlation between fat absorption and height $(r=0.045, p>0.05)$. Body weight, BMI and WHtR correlated significantly with liposuction volume $(r=0.608,0.646$ and 0.699 , respectively, $p<0.05)$, while WC displayed the strongest correlation $(r=0.705, p<0.05)$, thus suggesting that the size of preoperative WC may be the most important factor in determining liposuction volume, not BMI and WHtR. Based on that, in order to ensure the robustness of the data, outliers were removed for analysis, and the results were consistent with the above results (Table S2). 
Besides, there exhibited high correlations between BMI and weight $(r=0.897, P<0.01)$, between $\mathrm{BMI}$ and WC $(r=0.8, P<0.01)$, between BMI and WHtR $(r=0.820, P<0.01)$, and between WC and WHtR $(r=0.928, P$ $<0.01)$. The above cross correlation suggested that there may be a collinear relationship between these preoperative measurements.

\section{Partial correlations between preoperative measurements and fat volume}

Adjusted for WC, weight, $\mathrm{BMI}$ and $\mathrm{WHtR}$, partial correlation analysis was performed to evaluate the association between preoperative measurements and liposuction volume. As shown in Table 2. the correlation coefficients between all included variables and fat extraction declined to some extent, no matter which variables were adjusted. In addition, when WC was adjusted, the correlation coefficients between such variables as body weight, $\mathrm{BMI}$, WHtR and fat volume were most significantly reduced, from 0.608 to 0.079 , from 0.646 to 0.193 , from 0.699 to 0.144 , respectively, indicating that WC was the most important factor in determining fat volume. Also, we got rid of the outliers and the same results were found.

\section{Multiple linear regression analysis}

Multiple linear regression models were used to evaluate the association between WC and liposuction volume. At the same time, the non-adjusted and adjusted models are shown in Table 3. In the crude model, WC displayed significant correlation with liposuction volume ( $\beta=108.36,95 \% \mathrm{Cl}$ : 101.35 to $115.38, P<0.0001)$. In the minimally adjusted model (adjusted age), the effect size did not show obvious changes $(\beta=110.32,95 \% \mathrm{Cl}: 103.18$ to $117.46, P<0.0001)$. Nevertheless, after adjusting for other covariates, we did not detect any connection in a fully adjusted model $(\beta=250.79,95 \% \mathrm{Cl}:-126.12$ to $627.70, P=0.1926)$. To ensure the robustness of data analysis, we also handled $W C$ as a categorical variable (quintile) and found the same trend ( $p$ for the trend was 0.582 ).

\section{Relationship between WC and fat volume in subgroup analyses}

Interactions with all covariates are presented in Figure 5. Subgroup analyses showed that the association of WC with fat volume remained stable in different subgroups when grouped by age, height, weight, BMI, $W H t R$. There was evidence for an interaction between $W C$ and age ( $P$ for interaction $=0.0065)$. Besides, the tests for interactions were statistically significant for height, weight, BMI and WHtR with WC ( $\mathrm{P}$ for interaction $<0.05)$. The effect sizes of WC on fat volume showed significant differences in diverse degrees of obesity. Compared with normal BMI (<18.5) and lower BMI (18.5-24.0), the strongest effect size between WC and fat volume was observed on higher BMI (> 24.0) $(\beta=111.28,95 \% \mathrm{Cl}$ : 97.88 to 
124.69). Besides, WC was the most significantly associated with fat volume in individuals who had a higher WHtR ( $\beta=114.21,95 \% \mathrm{Cl}$ : 90.71 to 137.71$)$.

\section{Predicting total liposuction volume}

Because there was severe collinearity between the included variables, it is impossible to provide a viable equation for fat volume estimation. According to the amount of lipoaspirate, patients were divided into three surgical grades: level $1<3000 \mathrm{ml}$, level 2: $3000 \mathrm{ml}$ to $5000 \mathrm{ml}$ level $3>5000 \mathrm{ml}$. In these 742 cases, $68.60 \%$ of the patients' fat absorption was less than $3000 \mathrm{ml}, 26.95 \%$ was between $3000 \mathrm{ml}$ and $5000 \mathrm{ml}$, and only $4.45 \%$ was greater than $5000 \mathrm{ml}$, among which the maximum volume was $8300 \mathrm{ml}$. The WC was divided into nine consecutive groups with $5 \mathrm{~cm}$ equidistance, and fat volume sucked out was classified into three grades to form a contingency table (Table 4). The linear correlation trend test was carried out based on the two-way grade data (linear-by-linear association chi-square statistic, $X^{2}=535.282, d f=1 \rrbracket p$ $<0.001)$. The results showed that there was a significant linear correlation between WC group and fat aspiration grade group.

The bubble diagram of waist circumference and fat volume within the group can be seen in the Figure 6 . The liposuction volume of small WC group $(<90 \mathrm{~cm})$ was less than $3000 \mathrm{ml}$, and the liposuction volume exceeding $3000 \mathrm{ml}$ emerged with the increase of WC. Besides, the proportion of large WC group $(>105 \mathrm{~cm})$ was mainly accompanied by liposuction volume of level 2 and level 3 . The main trend indicated in this figure, with some variation, was that with greater WC, liposuction volume became larger. The GoodmanKruskal gamma test showed statistically significant positive correlations between the WC rankings and the degree of liposuction volume (gamma $=0.802, \mathrm{P}<0.001$ ), indicating that there was a high correlation and consistency between these two variables. The purpose of this study was to provide an evidence for WC to predict and estimate the grading distribution of liposuction volume.

Figure 7 displayed that the average liposuction volume in each group had a linear trend with the WC grouping, the Pearson correlation coefficient was $0.9817,95 \% \mathrm{Cl}: 0.9125$ to $0.9963(\mathrm{P}<0.001)$, and the linear regression formula was as follows: liposuction volume (mean) $=106.3 W C$ (mean)-7497; $P<0.001$, adjusted $\mathrm{R}^{2}=0.9638$. However, Figure 8 showed that the variation coefficient of WC was relatively small, $1.07 \%-3.60 \%$, while the liposuction volume has a larger coefficient of variation, distributed in the range of $21.20 \%-37.30 \%$.

Although there was a linear correlation between WC and liposuction volume in each group, the variation of liposuction volume within the group was high, demonstrating that there were great differences in liposuction volume among individuals with the same WC. Therefore, it is impossible to accurately predict the liposuction volume in terms of the individuals' WC. However, it is feasible to predict the probability of liposuction volume grade distribution by the grouped WC.

\section{Discussion}


Advances in liposuction technique and a greater understanding of the physiologic fluid dynamics have enabled surgeons to remove increasing volumes of adipose tissue during a single surgical procedure(22). Despite these progresses, no recommended range of safe lipoaspirate volume has been elucidated before the operation. In the present study, we found that WC was the most importance factor in determining lipoaspirate volume (Spearman correlation coefficient, $r=0.706, p<0.01$ ). As was shown in the crude model and minimally adjusted model, WC was significantly associated with liposuction volume, when we handled WC as a categorical variable, the same trend was observed. Interestingly, we found that there was an interaction between BMI and WC, namely, BMI exerted an impact on the liposuction volume through WC, particularly in obese or overweight population (BMI > 24). Besides, there was clinical significance of grade prediction: the gamma coefficient between WC group and lipoaspirate group was 0.812 , with high correlation and consistency. Based on that, we proposed an equation to evacuate the lipoaspirate volume before liposuction: liposuction volume (mean) $=107.489 \mathrm{WC}$ (mean)-7586.898, providing an estimation of rank distribution. Currently, given the limited evidence in the literature, plastic surgeons often rely on the patients' physical conditions, personal experiences, government-issued restrictions, and the potential complications of surgery to estimate safe liposuction volume. And this study could provide assistance for surgeons to perform liposuction, as the deep and intermediate subcutaneous fat is considered to be sucked out.

We conducted a PubMed search using the keywords "waist circumference", "liposuction volume" "central obesity" and "subcutaneous fat", simultaneously. Guidelines of international societies have suggested WC measurement as the preferred method for central obesity (>102 cm in men and $88 \mathrm{~cm}$ in women)(23$25)$. And some studies have found that central obesity is positively associated with cardiovascular disease (CVD) risk and some other diseases $(26,27)$. Other studies showed that waist circumference decreased significantly after liposuction $\left(F_{3,24}=44.5, p<0.001\right.$; post hoc, all p's $\left.<0.03\right)(28-30)$. However, to our knowledge, very few studies have discussed the connection between WC and liposuction volume and provided an equation for lipoaspirate estimation.

Although body mass index (BMI) is the most frequently used measurement for obesity, an inherent limitation is that BMI is correlated with total body fat, and it does not reflect body shape or body fat distribution(31). Moreover, BMI fails to account the proportion of weight related to increased muscle or the distribution of excess fat within the body(32). Besides, according to a recent study in JAMA, as they age, women tend to lose bone and muscle mass and have more fat accumulation in the abdomen(33). Independent of $\mathrm{BMl}$, central obesity, characterized by the excessive abdominal fat, has been related to higher risk of mortality(26). And a large prospective cohort study has demonstrated that among 156624 postmenopausal women with normal-weight $\left(\mathrm{BMI}<25.0 \mathrm{~kg} / \mathrm{m}^{2}\right)$, those with central obesity were at higher risk of mortality compared with women with normal weight and no central obesity(34). In this analysis, BMI was significantly correlated with liposuction volume (Spearman correlation coefficient, $0.646 ; \mathrm{P}<$ 0.01), indicating BMI's association with aspirated fat, but it is the interaction between BMI and WC ( $P$ for interaction $<0.001$ ) that lead to this result. 
So, other anthropometric measurements have been developed to describe the extent of central obesity, such as WC, waist-height ratio (WHtR)(35). As an index for central obesity, WC reflects abdominal fat tissue but it cannot differentiate between visceral and subcutaneous fat depots. But WC is indeed genderspecific(36). Furthermore, as Bosy-Westphal A et al and Pinho CPS et al postulated, it was noted that the WC, regardless of the measurement site, was predominantly a subcutaneous fat index among women(37, 38). Moreover, Pinho CPS et al(38) proposed that the distribution of abdominal fat was heavily genderdependent. In brief, men tend to accumulate greater amounts of intra-abdominal adipose tissue, whereas women are prone to store more fat in subcutaneous depots(39). Based on that, researchers also found that for a given level of WC or BMI, women had higher levels of subcutaneous adipose tissue than men(40). Thus, it is more meaningful for women to have waist and abdominal liposuction, such a conclusion is consistent to our research population, and WC seems to be a good index for liposuction volume among women.

Our study has a number of strengths. First, we have established strict inclusion and exclusion criteria, namely, the characteristics of the study population and the waist and abdominal liposuction position were fixed, people received simple liposuction cosmetic surgery without combined surgery, which ensured that the data were homogeneous.

Second, our sample size was relatively large (742 patients), and to ensure the robustness of data analysis and explore the true relationship between WC and lipoaspirate volume, a series of statistical methods were used, including sensitivity analyses and subgroup analyses.

Third, this study was a retrospective study, including unavoidable potential confounders. Therefore, strict statistical adjustments based on the STROBE statement were used to minimize residual confounding. Fourth, we have put forward a prediction formula of grade distribution, providing clinical guidance for surgeons. Fifth, in order to reduce confounding, attempt has been made to standardize operative technique. All operations were done by the experienced senior surgeons who had receive the operation training.

There are limitations in our study. First, as an analytical retrospective study, this study provides only weak evidence of associations between WC and liposuction volume; it is difficult to distinguish cause and effect. Second, this study population contains only Chinese female participants, the data may be not generalizable to other ethnic groups. As a single-center trial, this study might not have the generalizability a multi-center trial typically retains. However, because most patients receiving liposuction are female in our center, the statistics of the male patients are limited. Third, in addition to waist circumference and $\mathrm{BMI}$, lipid aspiration is also affected by a variety of factors, such as the distribution of subcutaneous fat and visceral fat, the ratio of adipose tissue to connective tissue, patient requirements, surgical procedures, and surgeons' habits. Although we have taken a series of measures to control these confounding, for example, the liposuction standard was consistent in our center. However, in clinical practice, these factors are unavoidable, so we need to develop a more comprehensive clinical prediction model. Fourth, the development of imaging technologies, such as CT, three-dimensional (3D) imaging volumetric analyses and MRI, will be more accurate for the calculation of abdominal subcutaneous fat, 
and the application of big data, artificial intelligence and deep machine learning will be beneficial to lipid absorption prediction(41-44).

\section{Conclusion}

In this group of cases with the specific population, a single nationality, all adult women, and relatively fixed station, there was a medium-to-high correlation between liposuction volume and WC, weight, WHtR, $\mathrm{BMI}$ and other factors, among which the WC was the highest, 0.705 . P for interaction showed that other variables exerted an effect on the liposuction volume through the WC. There was a significant linear trend and consistency between the WC size group and the liposuction volume group. It was feasible to predict the grade level of liposuction volume by WC before operation. Therefore, WC was of great importance for the preoperative evaluation of waist and abdominal liposuction.

\section{Abbreviations}

LVL: large-volume liposuction

ASPS: The American Society of Plastic Surgeons

BMI: body mass index

WC: waist circumference

WHtR: waist-to-height ratio

CONSORT: The Consolidated Standards of Reporting Trials (CONSORT)

KS test: Kolmogorov-Smirnov test

CVD: cardiovascular disease

CT: computed tomography

3D: three-dimensional

MRI: magnetic resonance imaging

\section{Declarations}

\section{Ethics approval and consent to participate}

The study was approved by the Ethics Committee of Tangdu Hospital (No. K202103-05)

\section{Consent for publication}




\section{Availability of data and materials}

All data generated or analyzed during this study are included in this published article [and its supplementary information files].

\section{Competing interests}

We declare that we have no competing interests.

\section{Funding}

There was no funding in this paper.

\section{Authors' contributions}

(I) Conception and design: All authors; (II) Administrative support: None; (III) Provision of study materials or patients: Yuejun Li; (IV) Collection and assembly of data: All authors; (V) Data analysis and interpretation: All authors; (VI) Manuscript writing: All authors; (VII) Final approval of manuscript: All authors.

\section{Acknowledgements}

Not applicable

\section{Authors' information}

Not applicable

\section{References}

1. Surgeons ASoP. Plastic Surgery Statistics Report. Data comes from the ASPS National Clearinghouse of Plastic Surgery Procedural Statistics. 2019.

2. Wu S, Coombs DM, Gurunian R. Liposuction: Concepts, safety, and techniques in body-contouring surgery. Cleve Clin J Med. 2020;87(6):367-75.

3. Sailon AM, Wasserburg JR, Kling RR, et al. Influence of Large-Volume Liposuction on Metabolic and Cardiovascular Health: A Systematic Review. Annals of plastic surgery. 2017;79(6):623-30. 
4. Haeck PC, Swanson JA, Gutowski KAea. Evidence-based patient safety advisory: liposuction. Plastic and reconstructive surgery. 2009;124(4 Suppl):28S-44S.

5. Sherman JE FP, White H, Leifer D. . Blindness and Necrotizing Fasciitis after Liposuction and Fat Transfer. Plast Reconstr Surg 2010;126:1358-63.

6. El-Ali KM, Gourlay T. Assessment of the risk of systemic fat mobilization and fat embolism as a consequence of liposuction: ex vivo study. Plastic and reconstructive surgery. 2006;117(7):2269-76.

7. Fourme T V-BA, Loubières Y, et al. Early Fat Embolism after Liposuction. Anesthesiology. 1998;89:782-4.

8. Chiang $\mathrm{IH}$, Chang SC, Wang $\mathrm{CH}$. Management of necrotising fasciitis secondary to abdominal liposuction using a combination of surgery, hyperbaric oxygen and negative pressure wound therapy in a patient with burn scars. Int Wound J. 2017;14(6):989-92.

9. Heitmann C, Czermak C, Germann G. Rapidly fatal necrotizing fasciitis after aesthetic liposuction. Aesthetic plastic surgery. 2000;24(5):344-7.

10. Thamwiwat A, Sudhakar D, Paniagua D, et al. Suspected coronary fat embolism after liposuction. Catheter Cardiovasc Interv. 2018;92(7):E449-E52.

11. Patronella CK R-RA, Newall G. et al. Thromboembolism in High-Risk Aesthetic Surgery-Experience With 17 Patients in a Review of 3871 Consecutive Cases. Aesthet Surg J. 2008;28:648-55.

12. Rohrich RJ KJ, Janis JE, Beran SJ, et al. An update on the role of subcutaneous infiltration in suctionassisted lipoplasty-A review. Plastic and reconstructive surgery. 2003;111:926-7.

13. Wang G, Cao WG, Li SL, et al. Safe extensive tumescent liposuction with segmental infiltration of lower concentration lidocaine under monitored anesthesia care. Annals of plastic surgery. 2015;74(1):6-11.

14. Rohrich RJ, Leedy JE, Swamy R, et al. Fluid resuscitation in liposuction: a retrospective review of 89 consecutive patients. Plastic and reconstructive surgery. 2006;117(2):431-5.

15. Jain AK, Khan AM. Stroke volume variation as a guide for fluid resuscitation in patients undergoing large-volume liposuction. Plastic and reconstructive surgery. 2012;130(3):462e-9e.

16. Chia CT, Neinstein RM, Theodorou SJ. Evidence-Based Medicine: Liposuction. Plastic and reconstructive surgery. 2017;139(1):267e-74e.

17. Cantarelli J, Godoy MF. Safe limits for aspirate volume under wet liposuction. Obesity surgery. 2009;19(12):1642-5.

18. Kenkel JM, Lipschitz AH, Luby Mea. Hemodynamic physiology and thermoregulation in liposuction. Plastic and reconstructive surgery. 2004;114(2):503-13; discussion 14-5.

19. Trott SA BS, Rohrich RJ, Kenkel JM, et al. Safety considerations and fluid resuscitation in liposuction An analysis of 53 consecutive patients. Plast Reconstr Surg. 1998;102:2220-9.

20. Iverson RE, Lynch DJ, American Society of Plastic Surgeons Committee on Patient S. Practice advisory on liposuction. Plastic and reconstructive surgery. 2004;113(5):1478-90; discussion 91-5. 
21. Notice of the General Office of the Ministry of Health on Printing and Distributing the Catalogue of Hierarchical Management of Medical Cosmetic Projects. [EB/OL]. [2009-12-11]. General Office of the Ministry of Health Department of Medical Administration (2009) No. 220.,http://www.gov.cn/gzdt/2009-12/25/content_1496781.htm.

22. Stephan PJ, Kenkel JM. Updates and advances in liposuction. Aesthetic surgery journal. 2010;30(1):83-97; quiz 8-100.

23. Alberti KG, Eckel RH, Grundy SMea. Harmonizing the metabolic syndrome: a joint interim statement of the International Diabetes Federation Task Force on Epidemiology and Prevention; National Heart, Lung, and Blood Institute; American Heart Association; World Heart Federation; International Atherosclerosis Society; and International Association for the Study of Obesity. Circulation. 2009;120(16):1640-5.

24. Expert Panel on Detection E, and Treatment of High Blood Cholesterol in Adults. Executive Summary of The Third Report of The National Cholesterol Education Program (NCEP) Expert Panel on Detection, Evaluation, And Treatment of High Blood Cholesterol In Adults (Adult Treatment Panel III). JAMA. 2001;285:2486-97.

25. Fang $H$, Berg $E$, Cheng $X$, et al. How to best assess abdominal obesity. Current opinion in clinical nutrition and metabolic care. 2018;21(5):360-5.

26. Zhang C, Rexrode KM, van Dam RM, et al. Abdominal obesity and the risk of all-cause, cardiovascular, and cancer mortality: sixteen years of follow-up in US women. Circulation. 2008;117(13):1658-67.

27. Coutinho T, Goel K, Correa de Sa D, et al. Central obesity and survival in subjects with coronary artery disease: a systematic review of the literature and collaborative analysis with individual subject data. J Am Coll Cardiol. 2011;57(19):1877-86.

28. Chin SH MW, Matarasso A. Do waistline and umbilical position really change after abdominoplasty? Plast Reconstr Surg. 2010;125:27e-8e.

29. Geliebter A, Krawitz E, Ungredda T, et al. Physiological and Psychological Changes Following Liposuction of Large Volumes of Fat in Overweight and Obese Women. J Diabetes Obes. 2015;2(4):1-7.

30. Cohen SR, Weiss ET, Brightman LAea. Quantitation of the results of abdominal liposuction. Aesthetic surgery journal. 2012;32(5):593-600.

31. Muller MJ. From BMI to functional body composition. European journal of clinical nutrition. 2013;67(11):1119-21.

32. Park J, Lee ES, Lee DY, et al. Waist Circumference as a Marker of Obesity Is More Predictive of Coronary Artery Calcification than Body Mass Index in Apparently Healthy Korean Adults: The Kangbuk Samsung Health Study. Endocrinol Metab (Seoul). 2016;31(4):559-66.

33. Rubin R. Postmenopausal Women With a Normal BMI Might Be Overweight or Even Obese. JAMA. 2018;319(12):1185-7. 
34. Sun Y, Liu B, Snetselaar L, et al. Association of Normal-Weight Central Obesity With All-Cause and Cause-Specific Mortality Among Postmenopausal Women. JAMA Netw Open. 2019;2(7):e197337.

35. Lee WS. Body fatness charts based on BMI and waist circumference. Obesity (Silver Spring). 2016;24(1):245-9.

36. Camhi SM, Bray GA, Bouchard Cea. The relationship of waist circumference and BMI to visceral, subcutaneous, and total body fat: sex and race differences. Obesity (Silver Spring). 2011;19(2):4028.

37. Bosy-Westphal A, Booke CA, Blocker Tea. Measurement site for waist circumference affects its accuracy as an index of visceral and abdominal subcutaneous fat in a Caucasian population. The Journal of nutrition. 2010;140(5):954-61.

38. Pinho CPS DA, Arruda IKG, Leite APDL, et al. Waist circumference measurement sites and their association with visceral and subcutaneous fat and cardiometabolic abnormalities. Arch Endocrinol Metab. 2018;62:416-23.

39. Palmer BF, Clegg DJ. The sexual dimorphism of obesity. Molecular and cellular endocrinology. 2015;402:113-9.

40. Grundy SM, Neeland IJ, Turer AT, et al. Waist circumference as measure of abdominal fat compartments. J Obes. 2013;2013:454285.

41. Linder N, Michel S, Eggebrecht T, et al. Estimation of abdominal subcutaneous fat volume of obese adults from single-slice MRI data - Regression coefficients and agreement. European journal of radiology. 2020;130:109184.

42. Grainger AT, Krishnaraj A, Quinones $\mathrm{MH}$, et al. Deep Learning-based Quantification of Abdominal Subcutaneous and Visceral Fat Volume on CT Images. Acad Radiol. 2020.

43. Lee SJ, Liu J, Yao J, et al. Fully automated segmentation and quantification of visceral and subcutaneous fat at abdominal CT: application to a longitudinal adult screening cohort. Br J Radiol. 2018;91(1089):20170968.

44. Wang Y, Qiu Y, Thai T, et al. A two-step convolutional neural network based computer-aided detection scheme for automatically segmenting adipose tissue volume depicting on CT images. Computer methods and programs in biomedicine. 2017;144:97-104.

\section{Tables}




\section{Table 1}

Descriptive Statistics of the demographic and clinical data $(\mathrm{N}=742)$ Minimum Maximum Mean SD Median IQR Mode $P$ value of SW test

\begin{tabular}{lllllllll} 
Age (years) & 18 & 59 & 36.34 & 8.73 & 37 & 12.25 & 39 & $<0.001$ \\
\hline Height $(\mathrm{cm})$ & 150 & 180 & 162.07 & 4.45 & 162 & 5 & 160 & $<0.001$ \\
\hline Weight $(\mathrm{kg})$ & 47 & 132 & 63.51 & 9.42 & 62 & 11 & 60 & $<0.001$ \\
\hline WC $(\mathrm{cm})$ & 76 & 134 & 95.87 & 7.89 & 95 & 10 & 91 & $<0.001$ \\
\hline BMI $\left(\mathrm{kg} / \mathrm{m}^{2}\right)$ & 17.3 & 44.08 & 24.16 & 3.23 & 23.56 & 3.68 & 25.39 & $<0.001$ \\
\hline WHtR & 0.45 & 0.83 & 0.59 & 0.05 & 0.59 & 0.03 & 0.6 & $<0.001$ \\
$\begin{array}{l}\text { Fat Volume } \\
(\mathrm{ml})\end{array}$ & 1000 & 8300 & 2606.73 & 1142.6 & 2350 & 1800 & 2000 & $<0.001$
\end{tabular}

WC, waist circumference BMI, body mass index WHtR, waist-to-height ratio SD, Standard Deviation IQR, Inter-Quartile Range

\begin{tabular}{|c|c|c|c|c|c|}
\hline Partial corr & ation coeff & cient between $\mathrm{f}$ & $\begin{array}{l}\text { Table } 2 \\
\text { t volume and preop }\end{array}$ & erative measurer & ents ( $N=742$ ) \\
\hline & None & Adjusted WC & Adjusted Weight & Adjusted BMI & Adjusted WHtR \\
\hline $\mathrm{WC}(\mathrm{cm})$ & $0.705^{\star \star}$ & & 0.460 ** & $0.409 * *$ & $0.231^{* *}$ \\
\hline Weight(Kg) & 0.608 * & $0.079 *$ & & $0.066^{*}$ & $0.271^{\star *}$ \\
\hline $\mathrm{BMI}(\mathrm{kg} / \mathrm{m} 2)$ & 0.646 ** & $0.193^{\star *}$ & $0.294^{\star *}$ & & $0.204^{\star \star}$ \\
\hline $\mathrm{WHtR}$ & $0.699 * *$ & $0.144^{\star *}$ & $0.490 * *$ & $0.378^{\star *}$ & \\
\hline
\end{tabular}




\section{Table 3}

Relationship between WC and liposuction volume in different models

\begin{tabular}{|c|c|c|c|c|c|c|}
\hline Variable & $\begin{array}{l}\text { Crude model } \\
\beta(95 \% \mathrm{Cl})\end{array}$ & P Value & $\begin{array}{l}\text { Minimally } \\
\text { adjusted model } \\
\beta(95 \% \mathrm{Cl})\end{array}$ & P Value & $\begin{array}{l}\text { Fully } \\
\text { adjusted } \\
\text { model } \\
\beta(95 \% \mathrm{Cl})\end{array}$ & $\begin{array}{l}\mathrm{P} \\
\text { Value }\end{array}$ \\
\hline WC & $\begin{array}{l}107.77 \\
(100.79 \\
114.75)\end{array}$ & $<0.0001$ & $\begin{array}{l}109.45(102.35 \\
116.54)\end{array}$ & $<0.0001$ & $\begin{array}{l}259.55 \\
(-116.41 \\
635.51)\end{array}$ & 0.1764 \\
\hline \multicolumn{7}{|c|}{ WC(quintile) } \\
\hline Q1 & Referent & & Referent & & Referent & \\
\hline Q2 & $\begin{array}{l}369.60 \\
(189.84 \\
549.36)\end{array}$ & $<0.0001$ & $\begin{array}{l}394.70(213.64, \\
575.77)\end{array}$ & $<0.0001$ & $\begin{array}{l}-178.92 \\
(-358.51 \\
0.67)\end{array}$ & 0.0512 \\
\hline Q3 & $\begin{array}{l}914.71 \\
(724.00 \\
1105.42)\end{array}$ & $<0.0001$ & $\begin{array}{l}953.37(759.34 \\
1147.40)\end{array}$ & $<0.0001$ & $\begin{array}{l}-166.68 \\
(-403.27 \\
69.91)\end{array}$ & 0.1678 \\
\hline Q4 & $\begin{array}{l}1950.92 \\
(1770.28 \\
2131.57)\end{array}$ & $<0.0001$ & $\begin{array}{l}1995.60 \\
(1810.12, \\
2181.09)\end{array}$ & $<0.0001$ & $\begin{array}{l}-120.03 \\
(-453.97 \\
213.92)\end{array}$ & 0.4814 \\
\hline$P$ for Trend & $<0.001$ & & $<0.001$ & & 0.467 & \\
\hline
\end{tabular}

Crude model: we did not adjust other covariants

Minimally adjusted model: adjusted for age

Fully adjusted model: adjusted for age; height; weight; BMl; WHtR

Cl: confidence interval

$\mathrm{BMI}$, body mass index WHtR, waist-to-height ratio WC, waist circumference 


\begin{tabular}{|c|c|c|c|c|}
\hline & st circumferen & $\begin{array}{l}\text { Table } 4 \\
\text { and fat volume }\end{array}$ & ontingency & \\
\hline \multicolumn{5}{|c|}{ Fat volume (ml) } \\
\hline$W C \triangle \mathrm{cm} \rrbracket$ & $F<3000$ & $3000 \leq F<5000$ & $F \geq 5000$ & Total \\
\hline$W C<85$ & $27(100.0 \%)$ & 0 & 0 & 27 (100.0\%区 \\
\hline $85 \leq W C<90$ & $124(99.2 \%)$ & $1(0.8 \%)$ & 0 & 125 (100.0\%区 \\
\hline $90 \leq W C<95$ & $190(88.4 \%)$ & $25(11.6 \%)$ & 0 & 215 (100.0\%区 \\
\hline $95 \leq W C<100$ & $103(62.4 \%)$ & $61(37.0 \%)$ & $1(0.6 \%)$ & 165 (100.0\%区 \\
\hline $100 \leq W C<105$ & $46(38.7 \%)$ & $72(60.5 \%)$ & $1(0.8 \%)$ & 119 (100.0\%区 \\
\hline $105 \leq W C<110$ & $14(26.9 \%)$ & $26(50.0 \%)$ & $12(23.1 \%)$ & 52 (100.0\%区 \\
\hline $110 \leq W C<115$ & $3(15.8 \% \square$ & $8(42.1 \% \square$ & $8(42.1 \%)$ & 19 (100.0\%区 \\
\hline $115 \leq W C<120$ & $2(18.2 \% \square$ & $4(36.4 \%)$ & $5(45.4 \%)$ & $11(100.0 \% \bigotimes$ \\
\hline $120 \leq W C$ & 0 & $1(11.1 \%)$ & $8(88.9 \%)$ & 9 (100.0\%区 \\
\hline Total & 509 (68.6\%) & 198 (26.7\%) & $35(4.7 \%)$ & $742(100.0 \% 区$ \\
\hline
\end{tabular}

\section{Figures}
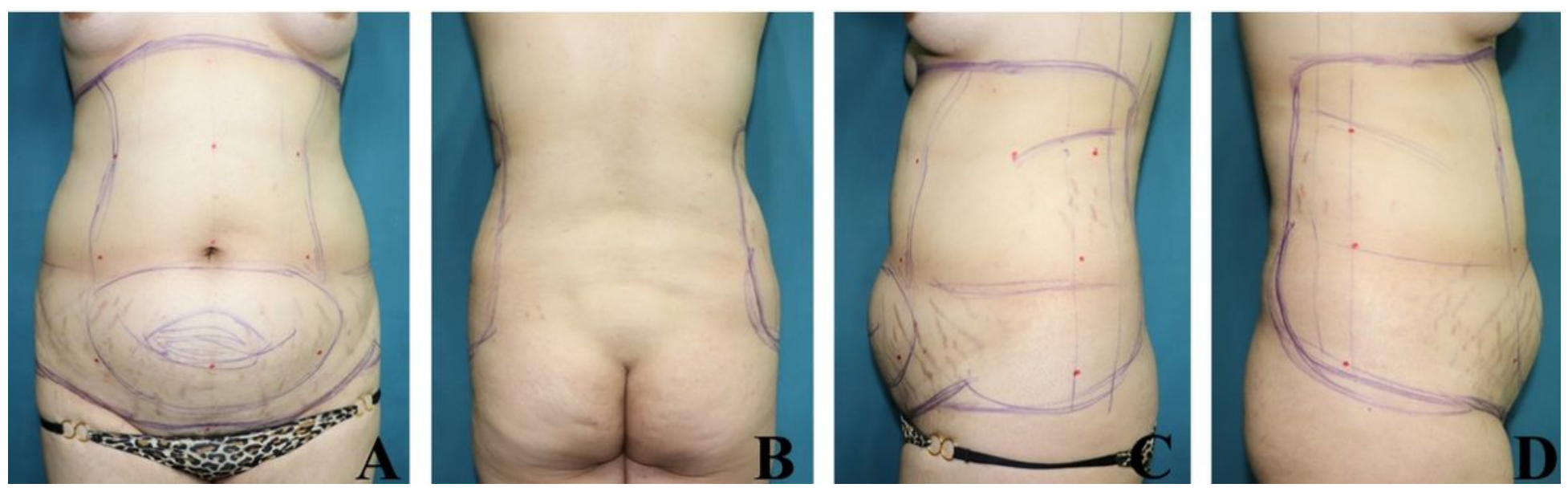

Figure 1

Liposuction range of waist and abdomen (A: front; $B$ : back; $C$ : left side; $D$ : right side) 


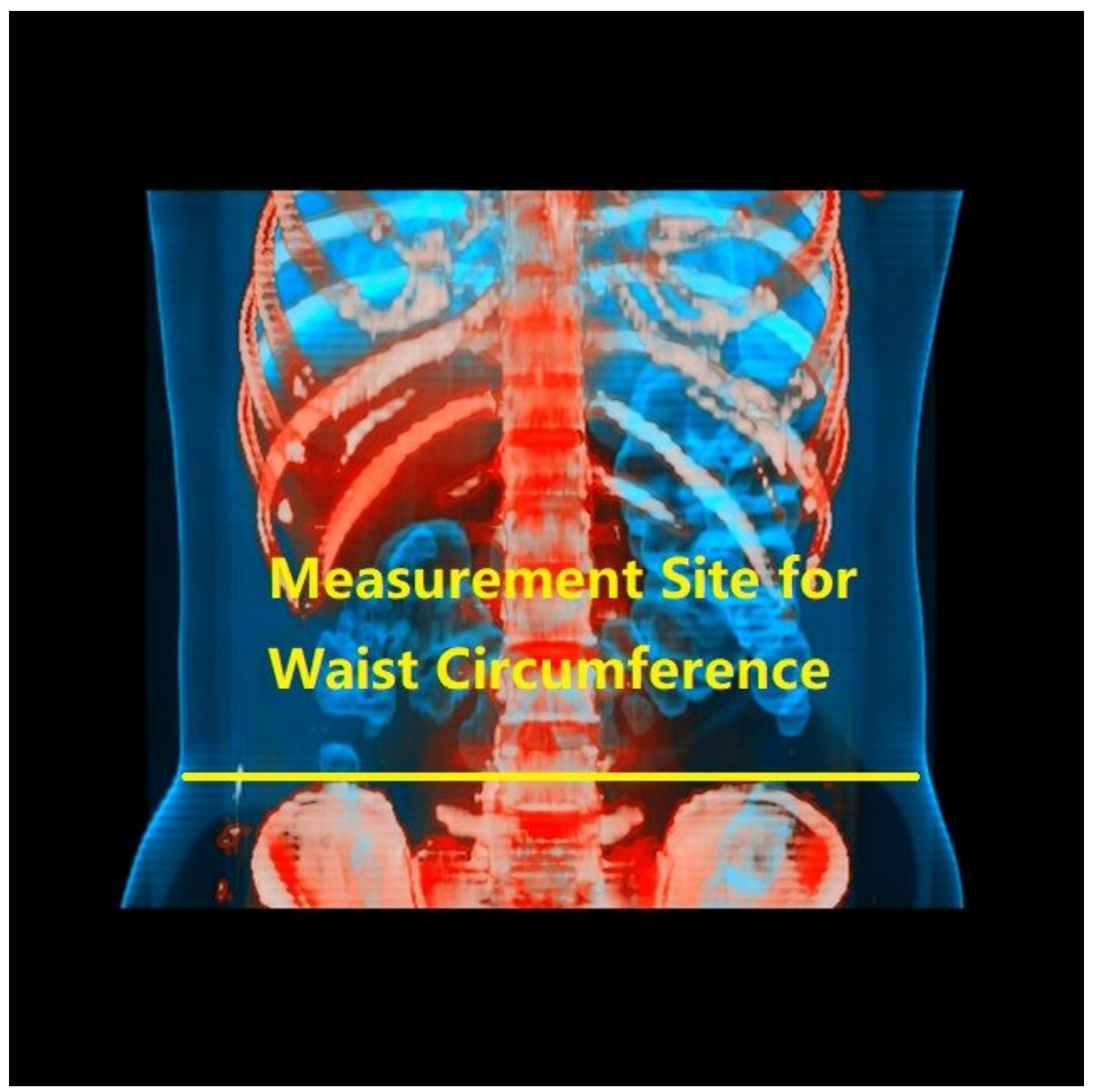

Figure 2

Measurement site for wasit circumference 

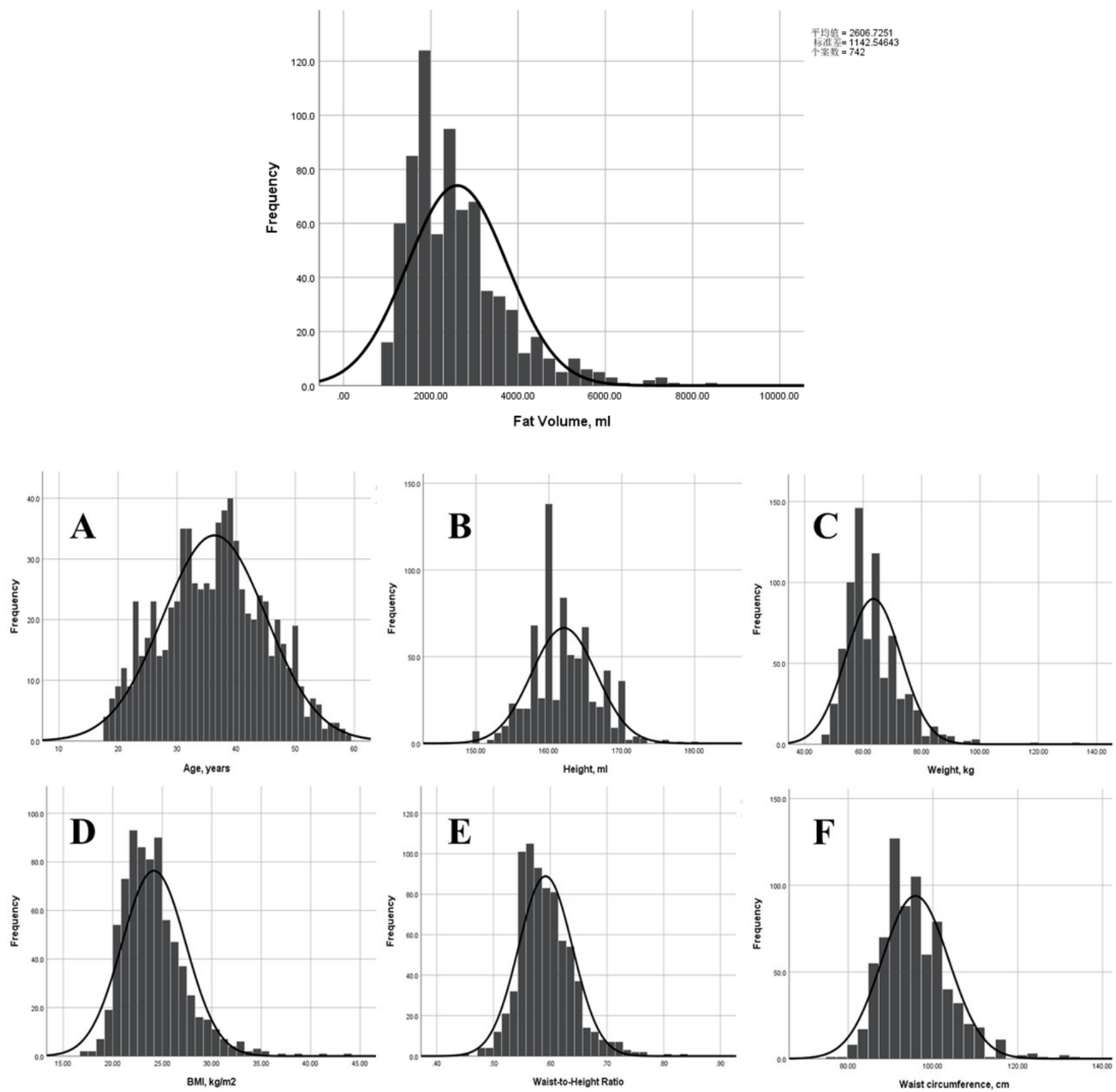

Figure 3

The frequency distribution of all included variables 


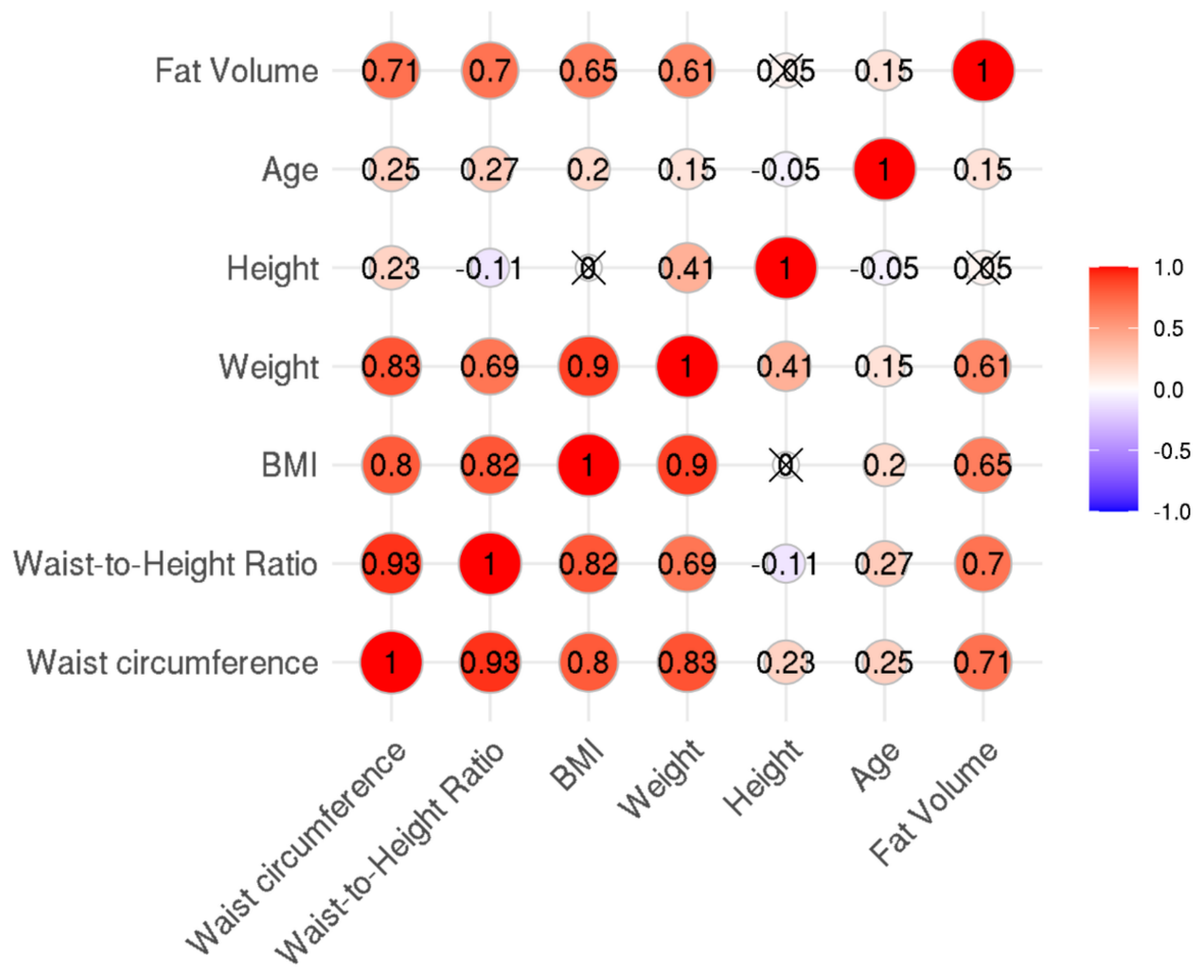

Figure 4

The Spearman correlation coefficient between anthropometric measurements and fat volume BMI, body mass index WHtR, waist-to-height ratio 


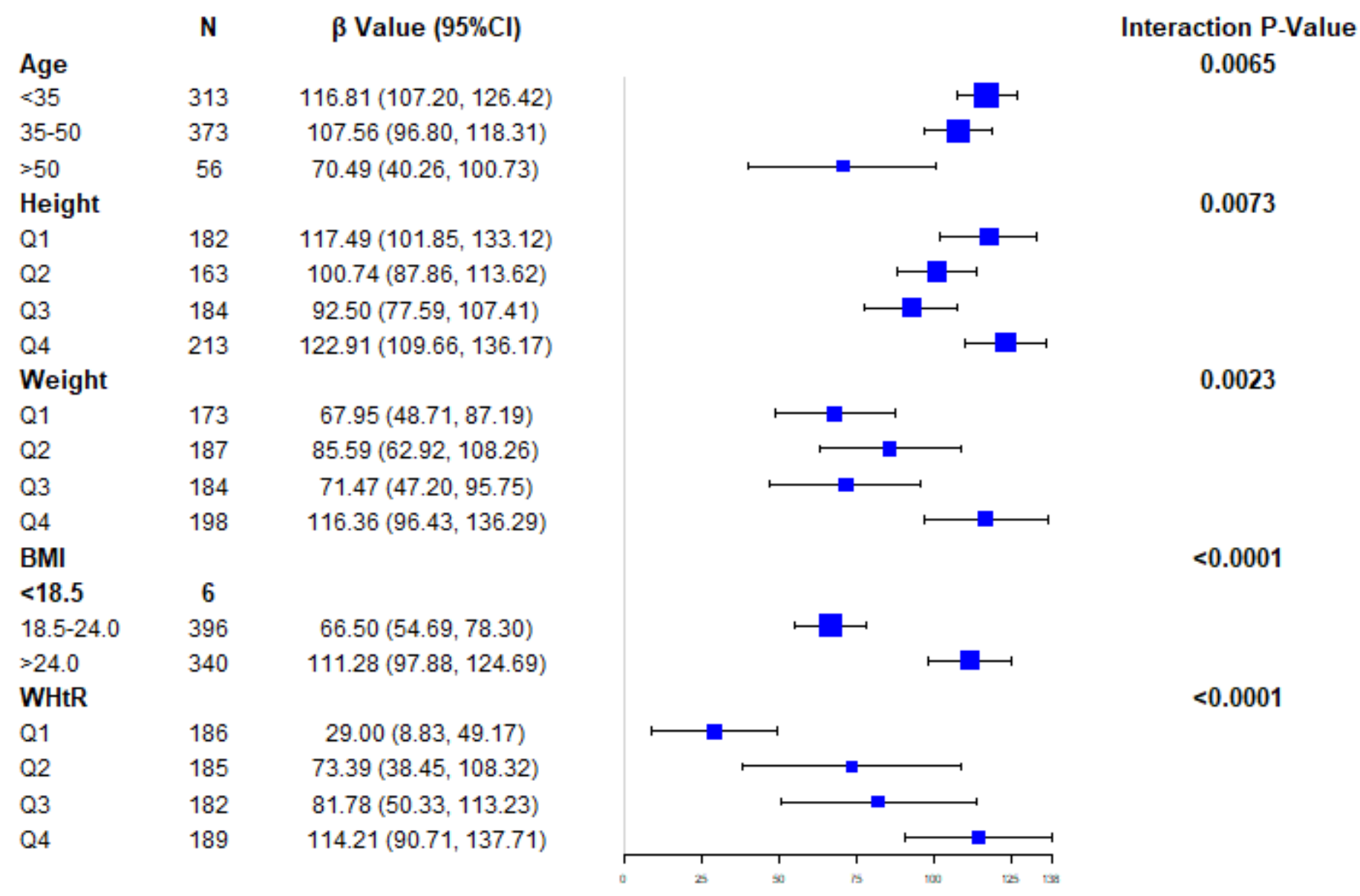

Figure 5

Effect size of waist circumference on fat volume in prespecified and exploratory subgroups According to WHO, Underweight (BMl<18.5 kg/m2) Normal Weight (BMl: 18.5-24.9 kg/m2) Overweight or Obesity $(>24.9 \mathrm{~kg} / \mathrm{m} 2)$ BMl: body mass index WHtR: waist-to-height ratio 


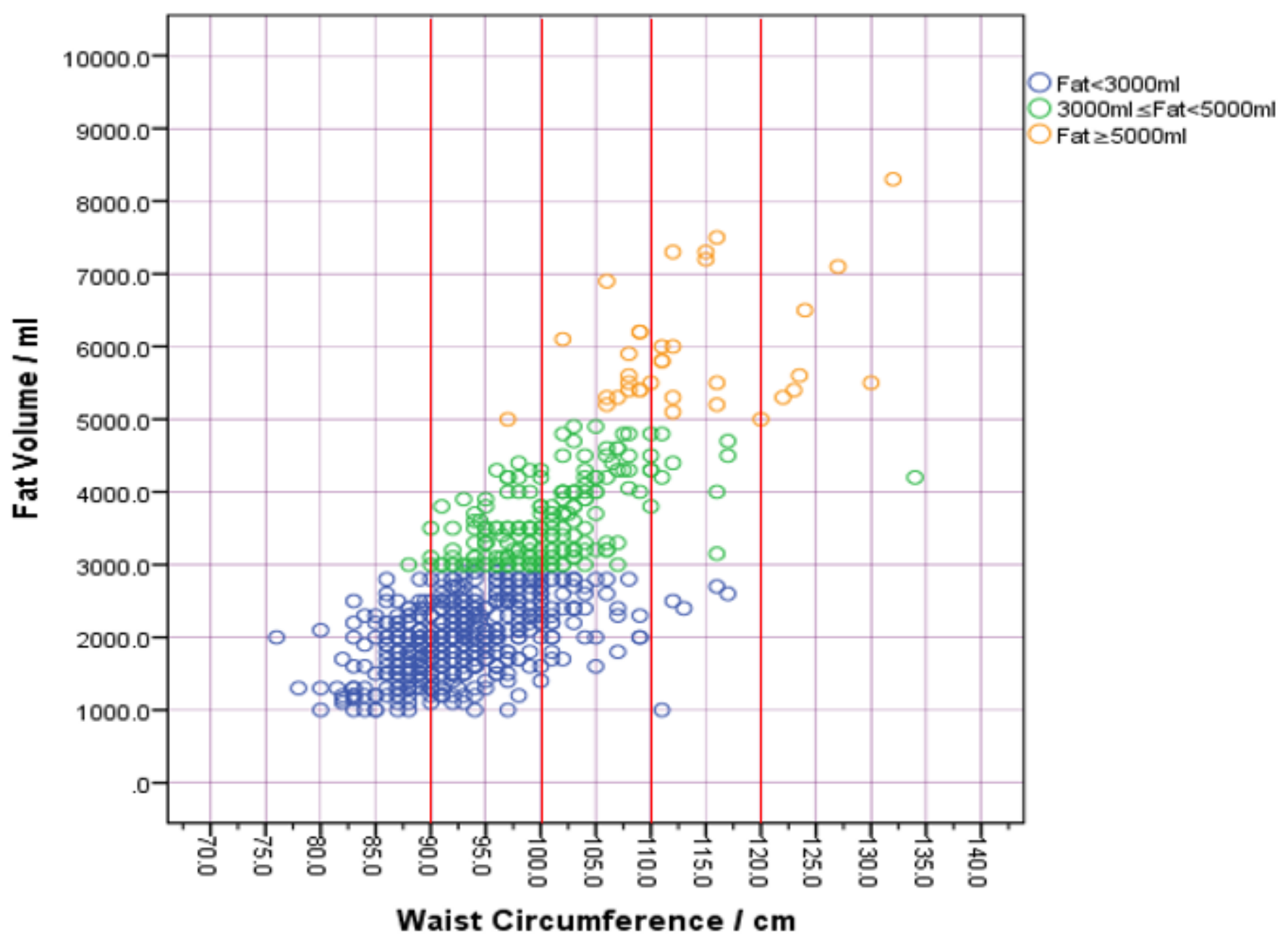

Figure 6

The bubble diagram of waist circumference and fat volume within the group 


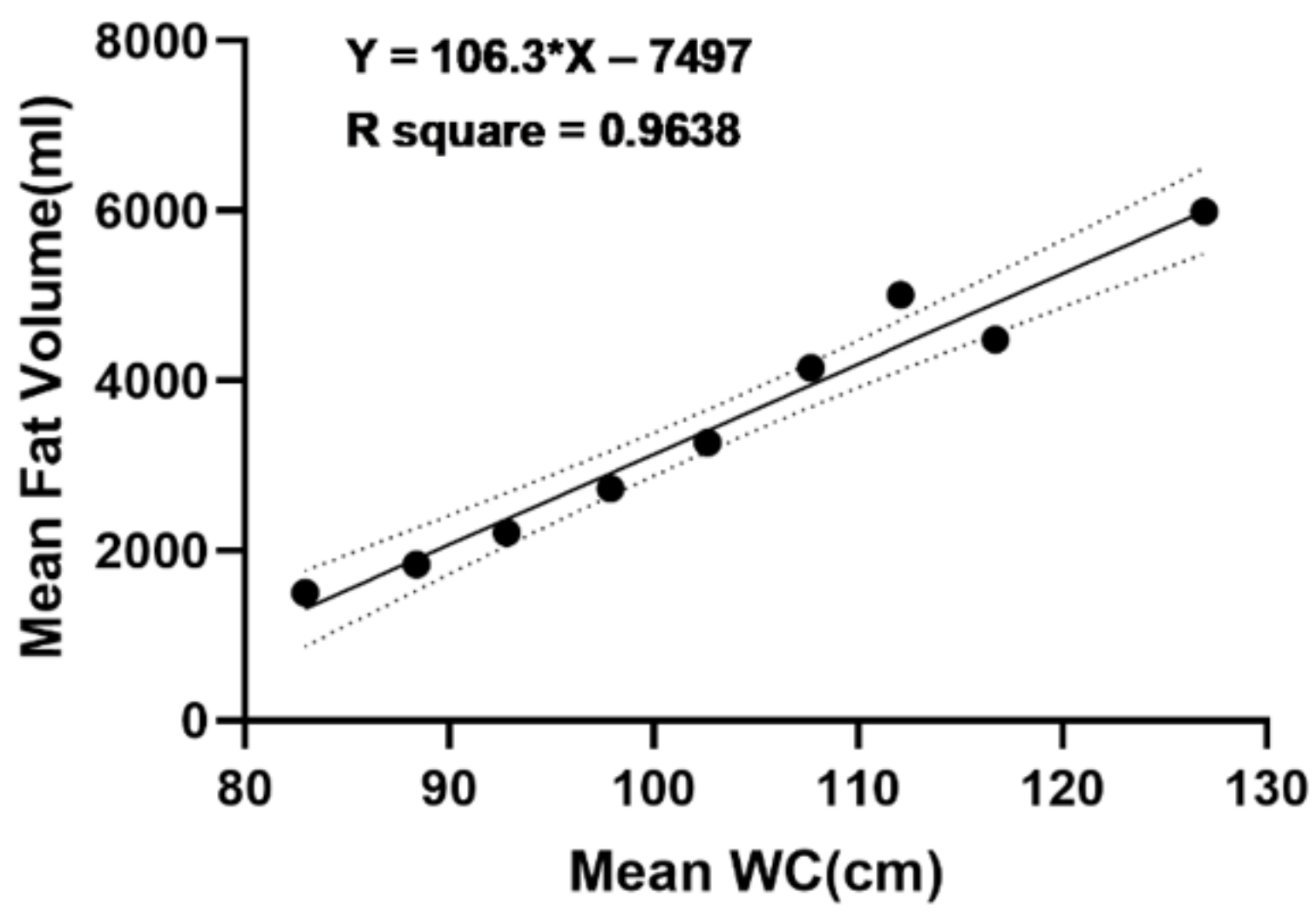

Figure 7

The fitting line between waist circumference (mean) and fat volume (mean) (Simple linear regression analysis was used to generate a line of best fit) 


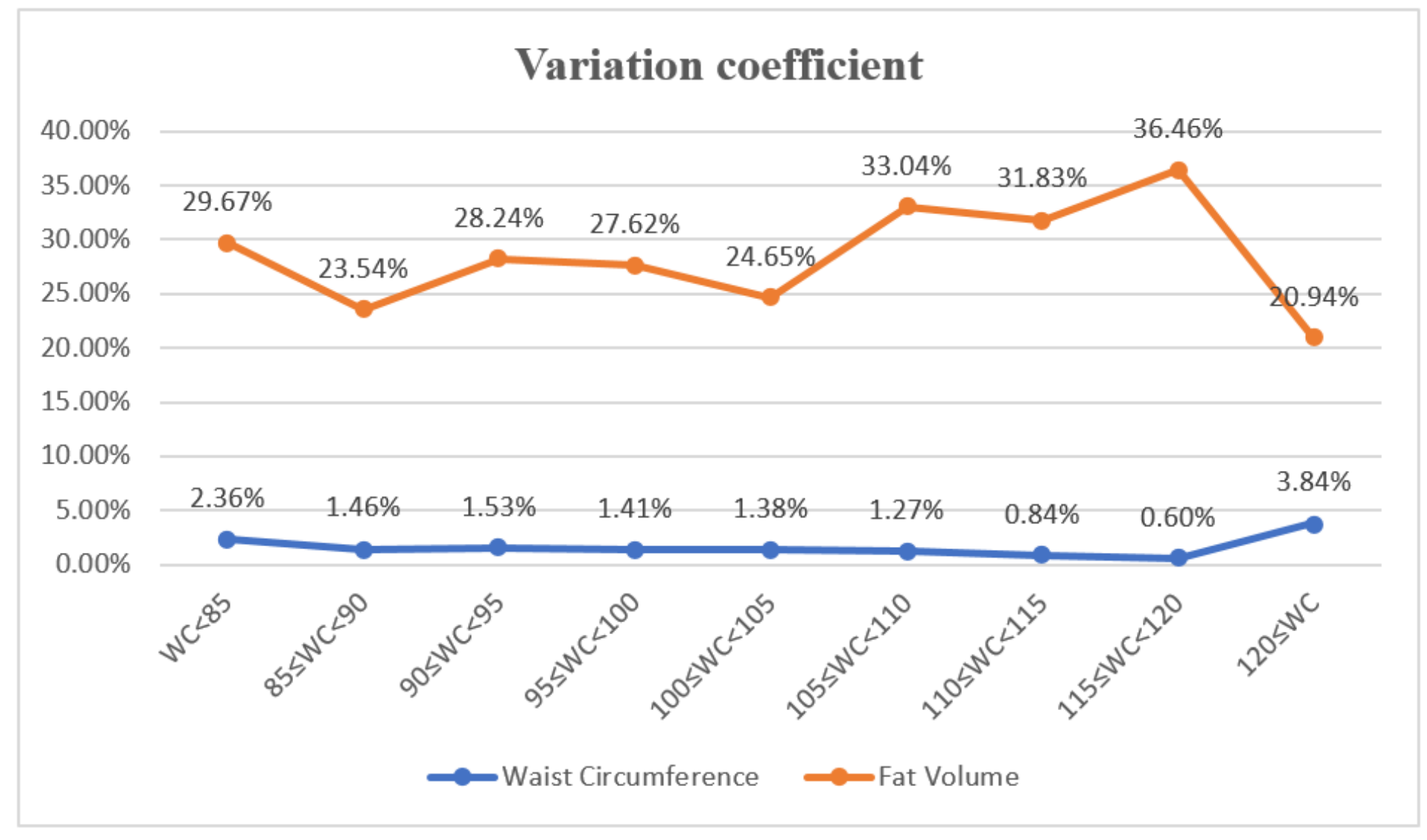

\section{Figure 8}

The variation coefficient of waist circumference and fat volume within the group

\section{Supplementary Files}

This is a list of supplementary files associated with this preprint. Click to download.

- STROBEChecklist.pdf

- Supplementarymaterials.docx 